\title{
ON MONOTONE ĆIRIĆ QUASI-CONTRACTION MAPPINGS
}

\author{
M. BACHAR AND M. A. KHAMSI
}

Abstract. We prove the existence of fixed points of monotone quasi-contraction mappings in metric and modular metric spaces. This is the extension of Ran and Reurings fixed point theorem for monotone contraction mappings in partially ordered metric spaces to the case of quasicontraction mappings introduced by Ćirić. The proofs are based on Lemmas ?? and ??, which contain two crucial inequalities essential to obtain the main results.

Mathematics subject classification (2010): Primary 47H09; Secondary 47H10.

Keywords and phrases: Fixed point, modular metric space, monotone mappings, quasi-contraction.

\section{REFERENCES}

[1] M. R. Alfuraidan, M. A. Khamsi, Caristi fixed point theorem in metric spaces with a graph, Abstract and Applied Analysis, Volume 2014 (2014), Article ID 303484, 5 pages.

[2] S. BANACH, Sur les opérations dans les ensembles abstraits et leurs application aux équations intégrales, Fund. Math. 3 (1922), 133-181.

[3] V. V. Chistyakov, Modular metric spaces, I: Basic concepts, Nonlinear Anal. 72 (1) (2010), 1-14.

[4] V. V. Chistyakov, Modular metric spaces, II: Application to superposition operators, Nonlinear Anal. 72 (1) (2010), 15-30.

[5] LJ. B. ĆIRIĆ, A generalization of Banach's Contraction Principle, Proc. Am. Math. Soc., 45 (1974), 267-273.

[6] J. Jachyms KI, The Contraction Principle for Mappings on a Metric Space with a Graph, Proc. Amer. Math. Soc. 136 (2008), 1359-1373.

[7] M. A. Khamsi, AND W. A. KiRK, An Introduction to Metric Spaces and Fixed Point Theory, John Wiley, New York, 2001.

[8] W. M. Kozlows Ki, Modular Function Spaces, Series of Monographs and Textbooks in Pure and Applied Mathematics, Vol. 122, Dekker, New York/Basel, 1988.

[9] J. J. Nieto, R. RodrigueZ-LopeZ, Contractive mapping theorems in partially ordered sets and applications to ordinary differential equations, Order 22 (2005), no. 3, 223-239.

[10] M. PǍCURAR, Iterative Methods for Fixed Point Approximation, PhD Thesis, "Babeş-Bolyai" University, Cluj-Napoca, 2009.

[11] O. POPESCU, Picard iteration converges faster than Mann iteration for a class of quasi-contractive operators, Mathematical Communications 12 (2007), 195-202.

[12] A. C. M. RAN, M. C. B. REURINGS, A fixed point theorem in partially ordered sets and some applications to matrix equations, Proc. Amer. Math. Soc. 132 (2004), no. 5, 1435-1443. 